\title{
The endogenous development of pastoral society: an anthropological case study in East Ujimqin Banner in Inner Mongolia
}

\author{
Kun Zhang $\mathbb{D} \cdot$ Hailin Shang
}

Received: 19 May 2020 / Accepted: 2 December 2020 / Published online: 10 December 2020 (C) The Author(s). 2020 Open Access This article is licensed under a Creative Commons Attribution 4.0 International License, which permits use, sharing, adaptation, distribution and reproduction in any medium or format, as long as you give appropriate credit to the original author(s) and the source, provide a link to the Creative Commons licence, and indicate if changes were made. The images or other third party material in this article are included in the article's Creative Commons licence, unless indicated otherwise in a credit line to the material. If material is not included in the article's Creative Commons licence and your intended use is not permitted by statutory regulation or exceeds the permitted use, you will need to obtain permission directly from the copyright holder. To view a copy of this licence, visit http://creativecommons.org/licenses/by/4.0/.

\begin{abstract}
Through empirical research on the social development of pastoral society in the East Ujimqin Banner, this study puts forward that within the government's "passive development" discourse, local herders would prefer to consciously practice "active development". This method both respects local culture and traditions, and triggers a shift from exogenous to endogenous development. My study shows that only by cultivating the self-development mechanism of ethnic minorities and the initiative to participate in development can we realize the social development of pastoral areas. The survival practices constructed by the local society according to its traditional mechanisms are not only connected with the external market and the state as modes of production, but also enable the local society's modes of livelihood to be maintained and the traditional social culture to continue amid the continuous transformation taking place under the impact of pastoral modernization.
\end{abstract}

\section{K. Zhang $(\bowtie)$}

School of Ethnology and Anthropology, Inner Mongolia Normal University, No.81, ZhaoWuDaRoad, Saihan district, Hohhot 010020, Inner Mongolia, China

e-mail: zsdxzhangkun@163.com

\section{H. Shang}

Department of Student Affairs, Inner Mongolia Normal University, No.81, ZhaoWuDaRoad, Saihan district, Hohhot 010020, Inner Mongolia, China 
Keywords East Ujimqin banner · Pastoral society $\cdot$ Livelihood · Endogenous development

\section{Introduction}

There are two main theoretical standpoints in the academic community when it comes to social development, namely, exogenous development, which stems from outside a community, and endogenous development, which is achieved by the community themselves. In the 1970s, the United Nations Economic and Social Council put forward a model that differed from the exogenous development model widely used in developing countries. This model later became the prototype for regional endogenous development, and stressed the impact that internal factors like equality, freedom, and economic democratization have on regional development. In 1975, the Swedish Dag Hammarskjöld Foundation published the Dag Hammarskjöld Report on Development and International Cooperation: What now? Another Development at the United Nations, which formally proposed the concept of endogenous development and expounded the significance of human beings, the environment, culture, ecology, and diversified development (Linstone H. A 1979: 95-96). After the 1980s, the research focus of the regional endogenous development theory gradually shifted from "material" to "human", putting people first. Hence, a reflection on endogenous development theory emerged from Japan. Tsurumi Kazuko and Kawata Tadashi defined endogenous theory from a sociological perspective and published Endogenous Development Theory (Kazuko and Tadash 1989:46-47).

As a synonym of "another development", endogenous development aims to explore development modes that are different from European and American modernization. Compared with exogenous development theory, endogenous development theory advocates using a strong foothold in the specific local ecosystems and traditions of a region to creatively transform the external factors affecting the region, and encourage its development. The Declaration of Madrid, released at the 2000 United Nations International Conference on a Culture of Peace, declared, on the basis of the four "new contracts", the necessity of promoting global endogenous development based on knowledge and internal capacities (Declaration of Madrid 2006).

In the field of Chinese Anthropology, Fei Xiaotong put forward his views on ethnic minority development as early as the 1980s. Fei held that development efforts among ethnic minority groups must pay attention to the unique physical and cultural advantages of the group themselves, giving them due power in the development of their region through the development of their social productivity and spiritual culture (Fei Xiaotong 1993:220). In fact, these thoughts on the development of Chinese society bring together a wide range of Fei Xiaotong's ideologies and research methods, such as rural community studies, differential pattern, small-town theory, regional development research, cultural awareness, and the pattern of diversity in unity of the Chinese nation.

In the past ten years, many Chinese scholars have proposed their views on regional social development, such as on exerting the autonomy of different regions 
over concentrating their funds and power in a direction that benefits regional development (Tu Renmeng 1993: 21-25). Moreover, scholars have posited that an endogenous development model combining the exogenous power of rural primary governmental organizations with the endogenous power of villages themselves has become the ideal form of Chinese rural development (Lu Xueyi 2001: 9). Therefore, in order to pursue sustainable development, it is necessary to empower local people (Wu Chongqing 2016: 6).

The above studies demonstrate that the regional endogenous development theory has become a new widely accepted perspective in academic circles both in China and beyond. These studies have been produced from a variety of academic background, providing a substantial theoretical and practical basis for anthropological research. However, few scholars have published results from applying this theory to the social development and anthropology of pastoral societies. Moreover, there are even fewer adequate case studies on the development of pastoral society. This study seeks to explore the systems that empower herders to actively change their situation as their region undergoes social transformation, by interpreting the diverse endogenous social development of pastoral areas. In so doing, the study aims to provide new cases to support the previous theoretical system and past research on pastoral development.

In practice, herders are usually remarkably good at making use of the original social mechanisms at their disposal, and combining traditional natural and social resources to find the best way to survive. This makes the endogenous development strategy an important way for them to adapt to social transformation and promote regional development. At present, by way of addressing the development of rural areas, the Chinese government has proposed a "rural revitalization strategy", which places rural pastoral development as the top priority for the government's future "three rural issues."1 Therefore, as a vital part of the development of ethnic regions in China, how can pastoral society transform the traditional nomadic lifestyles that have existed for thousands of years? How can we deal with the relationship between modernity and locality that underpins development discourse? What active strategies will the herders take to adapt to the rapid social transformation? What is the cultural logic behind the modernization of animal farming practices and the livelihoods adopted by herders? These issues must be the concern not only of policymakers, but also of academics.

\section{Field site and research methods}

The field site selected for this study is the East Ujimqin Banner, ${ }^{2}$ located in the eastern part of the Inner Mongolia Plateau and at the western slopes of the Greater Khingan Mountains. Its geographical location is bounded by the Hinggan League in the east, West Ujimqin Banner in the south, Abag Banner in the west and

\footnotetext{
${ }^{1}$ These "issues" refer to: increasing rural income, advancing agricultural development, and improving rural stability.

2،"Banner" is a type of county-level administrative area unique to Inner Mongolia.
} 
Sükhbaatar Province in the north. The total area is $47,300 \mathrm{~km}^{2}$, including 69.17 million $m u\left(1 \mathrm{mu}=\right.$ appr. $\left.666.5 \mathrm{~m}^{2}\right)$ of natural pastures, $95 \%$ of which are available for grazing. At present, the East Ujimqin Banner has jurisdiction over 5 towns, 4 sumu towns, 9 township-level administrative districts, and the Wulagai agriculture and animal husbandry comprehensive development zone. There are 57 gacha settlements, 1 state-owned forest farm, 13 communities, 220 herder groups and 192 resident groups. ${ }^{3}$ As of 2016, the East Ujimqin Banner had a total population of 70,700 , a Mongolian population of 45,600 and a livestock rearing population of $33,000{ }^{4}$ The East Ujimqin Banner is a border animal husbandry area with ethnic Mongols as the main ethnic group.

Located in the hinterland of Xilingol Grassland, a relatively the grassland vegetation and nomadic livelihoods of the East Ujimqin Banner have been preserved in a relatively authentic way. Therefore, it is a National Key Ecological Function Area known as "the hometown of Mongolian long songs, the cradle of Mongolian wrestling, the capital of traditional ethnic clothing, a famous location for nomadic farmers and an ecological paradise". The modernization of animal husbandry in the area has achieved remarkable results in recent years, and the East Ujimqin Banner is a typical, representative example of the development of pastoral areas in China. The Ujimqin herders have lived a nomadic lifestyle for generations. Since the beginning of the 1980 s, the local pastoral society has been involved in a nationalized and market-oriented modern system, developing from nomadism to settlement and resettlement, then from assigning households with a certain price of livestock to contracting households with areas of grassland. Today, we can see a revitalization of pastoral areas and modernization of animal husbandry. Local people's livelihoods have experienced a historic process of rapid change and transformation. It is reasonable to argue that this change is not only influenced by the natural environment and historical conditions; it is also related to the regulation of multiple forces such as policies and markets.

In order to explore the characteristics of endogenous development and livelihood transformation in the pastoral society of East Ujimqin Banner, this study adopts the classic anthropological method of participant observation. In August 2011, August 2012 - September 2013, and August 2018, I conducted over a year of field research into the livelihood of animal husbandry and the social development of the East Ujimqin Banner. I also took a one-year post at the Bureau of Agriculture and Animal Husbandry in the East Ujimqin Banner. Therefore, the multiplicity of the author's roles in the field research, the diversity of the investigation sites, and the effectiveness of the progressive combination of government staff, researchers, and research subjects, have provided more favorable conditions for this research and multiple perspectives for observation. This has allowed me to carry out a progressive multi-point study across the entire East Ujimqin Banner area.

A traditional method in anthropological research is to use participant observation to conduct a meticulous, in-depth piece of research that dissects the ways of life of a village or community. Of course, this approach is typical of anthropological fieldwork,

\footnotetext{
${ }^{3}$ Source: Provided by the East Ujimqin Banner Population Bureau.

${ }^{4}$ East Ujimqin Banner Statistics Bureau: East Ujimqin Banner Statistical Yearbook, 2016.
} 
which habitually focuses on research of a microscopic level of detail. However, in doing so, the perspective of such research can become mired in detailed information specific to one small community, thus failing to achieve any overarching, holistic understandings or reflections. In his writing, Fei Xiaotong provided his own valuable reflections on anthropological research methods. He believed that the ethnographic method of anthropology in the past was inadequate, and we should instead adopt a research method that combines individual parts with the whole, considering different types and different levels of information in order to explain the manifold and integrative structure of the Chinese civilization system (Fei Xiaotong 2000: 9).

In the present paper, therefore, I did not confine the research perspective to a single community, but took the entire Banner as the study area. I selected a range of different geographical locations, types of vegetation, degrees of degradation, and livelihood status in East Ujimqin Banner, then carried out in-depth classification and comparison. This approach allows us to begin with the region's individual parts before studying the whole, systematically progressively clarifying the economic characteristics and cultural specialties of the entire pastoral society. Therefore, among the anthropological researches of pastoral areas, this study is positioned as a multi-point ethnography with the East Ujimqin Banner as its unit of study. The study aims to provide insightful breakthroughs and advances on the research methods formerly used for pastoral anthropology research on individual communities in the past.

\section{Results and discussion: development practices of pastoral society in the East Ujimqin Banner}

In the face of problems such as the degradation of grassland ecosystems, increasingly fragmented grassland area, and the constant impact and bombardment from modern systems such as the nation, the market, and technology, how can herders, as the main subject of this case study, adapt to the processes of change and transformation and maintain the continuity of their nomadic livelihoods and traditional culture. As Loye said, adaptation is beginning to be seen not as the result of changes to an organism determined by their environment, but instead as the result of an active response to perceived environmental restrictions exacted by the organism themselves (Loye 2004: 122). At the uncomfortable juncture between tradition and modernity, adaptation and selection, what kind of initiative and active features do the herders have at their disposal, and what kind of attributes are unique to this group? It is with these questions in mind that we embark on our discussion.

The initial attempt: changes in development concepts and management practices

After the grasslands and livestock were contracted to the household, the function of the household as an independent business unit has been strengthened beyond recognition. This new social environment has placed new demands on herders, endowing them with new responsibilities, obligations and roles to play. This means that the herders have been required to change their traditional ways of thinking and 
behaving, picking up new knowledge and skills, so as to adapt to the new natural environment and social culture, meanwhile maintaining the sustainability of a nomadic livelihood. Independent management and self-financing are the current realities that herders must face. Against the background of individualized livestock management and the constant improvement of market concepts, learning how to manage and how to maximize the benefits of these changes have become the key to every herder family's survival. As a result, a number of herders took a flexible attitude and responded early, beginning their exploration towards prosperity and becoming the first pastoral elite to adapt to the new environment. After the division of local grasslands, Qinggeletu became the first person to attempt to change the management system and expand family herds.

\section{Case 1}

Qinggeletu, a 63-year-old Chinese Mongol, migrated from Tongliao to Arslan Gacha, Huretunao'er Sumu in 1968. The livestock distribution rule in 1983 was 15 sheep and 5 cattle per person. Qinggeletu has 5 siblings in his family. Together with their parents, the 7 of them were given 105 sheep and 35 cattle. In the second year, the grassland was divided into $2000 \mathrm{mu}$ per person. Qinggeletu's family received 14,000 mu of grassland in total. Qinggeletu is smart. He bought Ujimqin lamb rakes ${ }^{5}$ from the local area for 45 yuan a piece, and sold them to herders in Hulunbuir for 85 yuan each. With the money, he bought goats and lambs to increase the size of his herd. Due to the small size of the local Mongolian cattle, he spent 500-600 yuan on an improved fattened calf from northeastern China, and raised it to sell for 1200 yuan. The whole family worked painstakingly and after a few years, the herd quickly grew to over 2000 lambs and 500 cattle, making the family a typical example of the Banner's wealthy households.

In the East Ujimqin Banner, herders like Qinggeletu are not in the minority. At the beginning of the grassland distribution, each household originally received relatively few livestock, but due to market demand and the increasing price of livestock products, herders were compelled to expand their herds to increase their family income. In fact, as long as some herders benefit from the change in management methods, their surrounding contemporaries will begin to follow the trend, thus accelerating the socio-economic transformation and reform of the East Ujimqin Banner.

Furthermore, herders need to stock thousands of jin ( 1 jin = appr. $0.6 \mathrm{~kg})$ of fodder every August. This stockpiling is done in preparation for the winter to ensure that livestock can be kept fat and as many lambs as possible can be delivered successfully. During the summer, herders set aside a certain area of grassland to be used for hay making instead of grazing. If their pastures are seriously degraded and are insufficient for fodder reserves in winter and spring, they must buy grass and fodder from other herders. This shows that herders are aware of the effects of grassland degradation, which has rendered it impossible for the herds to maintain their physical strength and nutritional balance on their ordinary diet of grass alone. As a result, it is necessary to

\footnotetext{
${ }^{5}$ Lamb rake is how the herders call a ram.
} 
combine grazing with drylot feeding to survive. For herders who have lived a traditional nomadic lifestyle for generations, adapting their way of thinking has been a slow process; from relying completely on pasture grazing to combining grazing and supplementary feeding. Qingbate, who is responsible for distributing subsidies, told me about the initial attitude of the herders towards government subsidies:

"From 2003 to 2006, the government subsidized the herders with fodder because of the spring rest period from grazing. At that time, we were responsible for distributing corn seeds to herders at the health team's farmyard. Having just received their corn seeds, as soon as they left the farmyard many herders would sell their provisions on to the Han people in the Banner to feed their pigs. A bag of corn seed fodder worth 100 yuan would sell for just 30 yuan. At that time, they did not know about the fodder or its effects on livestock. They also said, 'Our sheep eat natural pasture, not those things.' Now, there's not one herder that doesn't know about the fodder, and every family comes to the Banner to buy truckloads of fodder to feed their sheep in the winter".

Therefore, during this process of constant learning, adaptation, change and selection, herders are doing all they can to maintain the traditional nomadic lifestyle while they transition from a total reliance on natural grazing to a combination of grazing and drylot feeding. Since ancient times, pastoral production has always followed the traditional herding custom of reasonably adjusting each family's herd structure according to the type of pasture in order to maintain the best conditions for the pasture to grow. The herd structure refers to the proportion of different breeds in the family herd, and the proportional composition of age and sex within one kind of livestock (Wang Jiange 2001: 47). Wang Jiange believes that the herd structure is not only a variable in ecological conditions, but also a variable in social structures, especially the Mongolian class structure. The discussion of herd structure here is mainly based on the proportions of different breeds in the family herd under specific ecological conditions. According to the amount of grazing, the herders of East Ujimqin Banner divided the five types of livestock into two types, large and small. Large animals include Mongolian horses, Mongolian cattle, and camels, and small animals are mainly Mongolian goats and sheep. In terms of utility, large animals used as working livestock, and small animals used as both dairy and meat livestock. They are also sold as commodities or as gifts for weddings and social gatherings.

According to the survey, the traditional "five key livestock" herd structure has changed since the 1980s. In general, the proportion of large animals decreases, and the proportion of small animals increases year by year. Among them, the proportion of sheep is increasing rapidly. At the end of 2015, the total number of livestock in the entire Banner was 1,642,634, including 127,766 large animals, 1,514,868 small animals, 80, 887 cattle, 46,066 horses, 813 camels, 1,433,441 sheep, and 80,887 goats. ${ }^{6}$ Based on the data obtained from the field survey of the East Ujimqin Banner, I conducted a statistical analysis on the composition of the entire Banner's herd population structure after the 1980s, taking 10 years as a statistical cycle (Fig. 1):

\footnotetext{
${ }^{6}$ Source: "Xilinguole League Statistical Yearbook", edited by the Xilinguole League Statistics Bureau, 2016.
} 


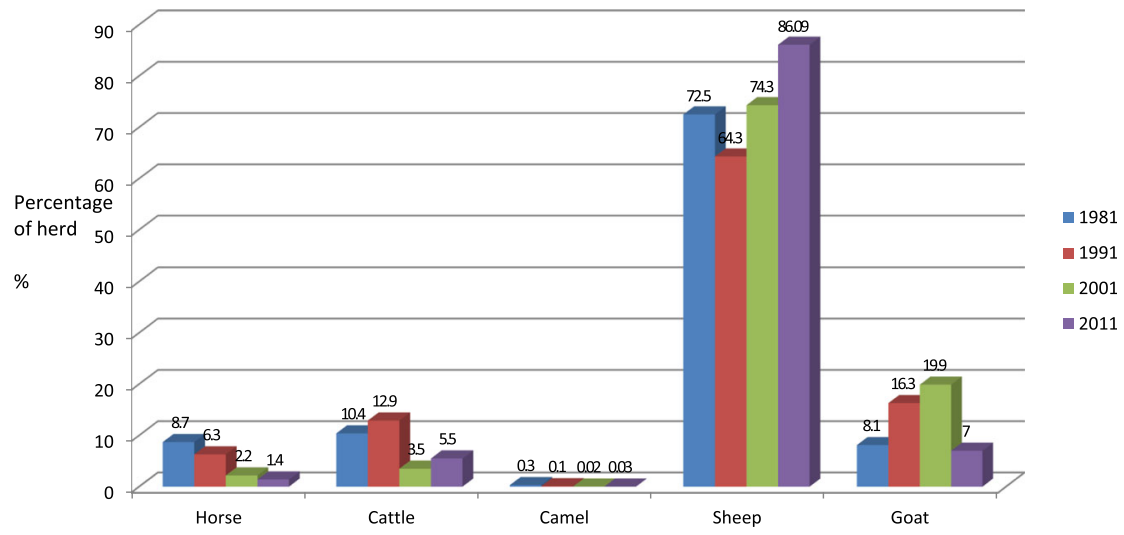

Fig. 1 Percentage composition of "five key livestock" in East Ujimqin Banner (Source: Calculated and compiled based on data obtained by Dongwu Qi Statistics Bureau and Local Records Office, 2016)

The above statistics show that from 1981 to 2011, the number of large animals-horses, cattle, and camels-decreased sharply year by year. Horses decreased from $8.7 \%$ of the total herd in 1981 to $1.4 \%$ in 2011 , cattle decreased from $10.4 \%$ to $5.5 \%$, and camels saw the most acute reduction, from $0.3 \%$ to $0.03 \%$. On the contrary, the number of small animals is growing rapidly. Among them, sheep increased from $72.5 \%$ to $86.09 \%$, and goats showed a trend of increasing at first, then decreasing. Goats increased from $8.1 \%$ in 1981 , to $16.3 \%$ in 1991 and $19.9 \%$ in 2001 , then decreased to $7 \%$ in 2011 . The reason for this unprecedented decrease is that goats are more active and prefer to eat grass roots. Not only can they easily cross through fences into the pastures of other herders, they can also cause serious damage to the grassland ecology. In addition, the price of cashmere has fluctuated greatly in recent years, so herders begun to continually reduce their goat population.

Therefore, we can see that in dispersed family operations, wherein people bear their own profits, losses, and risks, herders have begun to adjust their herd structures to expand the herd's size, which can quickly increase family income in the short term. The number of the "key five livestock" owned by a herder used to indicate which tribe they were a member of, as well as their social status. Now, however, the number of sheep in a herd has become a symbol of the herder's social status and living conditions. An important matter for herders is choosing when to sell their sheep. They always weigh up the sheep's price, then wait for the most opportune and profitable time to sell. In this regard, Lattimore once pointed out, "None of these livestock can provide a higher economic value to nomads on the grassland than sheep" (Lattimore 2005: 53). In view of this claim, I selected three cases from among 100 recorded interviews for further analysis. The selected cases came from different geographical locations, with different types of grassland vegetation, and different family economic conditions. 


\section{Case 2}

Wuenbaiyila, a 30-year-old ethnic Mongolian herder from Taidaomude Gacha, Wuliyasi. He was born in 1984, the year after grassland contracting was introduced. Therefore, he did not receive any grasslands himself. After his father died, his mother gave him 3119 mu of grassland. Wuenbaiyila's wife had no grassland. At present, there are 304 sheep in the family, including 200 ewes, 60 large lambs, 40 small lambs, 4 sheep rakes, and no goats. In addition, there are 2 horses used for grazing during the heavy winter snows, and 4 cows for milk and dairy production.

\section{Case 3}

Hobart, a 45-year-old ethnic Mongolian herder from Mandulatu Gacha, Samai Sumu. In 1984, when the local grassland was divided, $1225 \mathrm{mu}$ were allocated to each person. Hobart's family of four received $4900 \mathrm{mu}$ of grassland and rented a further $4000 \mathrm{mu}$ from other herders. There are currently 1300 sheep in the family, including 20 sheep rakes, no cattle or goats, and 2 horses, mainly used for Nadam exhibitions and horse racing during the Obo Festival.

\section{Case 4}

Siren, a 62-year-old ethnic Mongolian herder from Shangdu Gacha, Gadabuqizhen. In 1983, when the local grasslands were divided into $1969 \mathrm{mи}$ per person, Siren and his mother, younger brother, wife, and four children, a total of 8 people, received 15,752 ти of grassland. Now that his mother and brother have passed away, the grassland of the family of six has not been separated. There are more than 1000 sheep in Siren's herd, including over 20 goats, but no cattle or horses.

The above cases show that the herders in the central part of the East Ujimqin Banner (see Case 2) mainly raise sheep, no goats, two horses, and four cattle. The herders of Case 3, living in the north of the East Ujimqin Banner, also raise sheep as the main livestock, as well as 2 horses, but no cattle or goats. The herders of Case 4 in the west only raise sheep and goats, but no cattle or horses. It can be seen that the composition of herds is mainly dominated by small animals. In sheep, this mainly consists of ewes, supplemented by rams and goats. Large animals such as cattle, horses, and camels have largely been expelled from the family herd structure for their long rearing cycles and low economic benefits. Small animals are mainly represented by sheep, which have seen a substantial increase in number and proportion within the herd. This strong representation of sheep is connected to the animal's increasingly important position in the life of herders, because sheep breed fast, have short feeding periods, high economic benefits, and a large competitive advantage in the market. Herders, who have been introduced to the market system in a short space of time, have begun to rely more and more on the market and economic liquidity, striving to participate in the market economy in order to increase family income. 
Technological integration \& livelihood transformation: modernization of pastoral mode of production

My investigation has also found that many herders, under the encouragement and guidance of local policies, have been actively engaging in modern livestock production. This is shown in how they have modernized and industrialized the livestock production methods and technologies, utilizing the excellent resources available in the grasslands to transform the way they breed and feed their livestock. While we investigate to how pastoral livelihoods have changed, we must also pay attention to the significant impact modern technology has had on these traditional livelihoods. Modern technological devices such as grass trimmers and hay rakes, automatic milking pumps, mechanized shearing machines and solar-powered motor homes are being increasingly integrated into traditional pastoral mode of production. Interviewees told me that before 2009, they could only trim their grasslands by hand. This was before they had modernized mechanical devices like grass trimmers, hay rakes and balers at their disposal. Now, however, almost all the herders have used mechanical devices to cut their grasslands. If any households lack such devices, they usually employ temporary workers to trim and bale the grass. In order to reduce of independently hiring temporary workers, such households often choose to hire these workers in cooperation, or by lending each other hay rakes for communal use. With this, herders have managed to blend their traditional cooperative organizational mechanisms into a modern technological system.

White theorized that culture is a dynamic system; It can move and evolve when provided with energy (Shupin and Peihua 1998: 287). White also divided culture into three sub-systems, namely the technical system, social system and ideological system. He pointed out that they both interrelate and interact with each other. Among them, the technical system plays a leading role because people require technical means in order to survive in nature. Nowadays, based on traditional grazing, herders have begun to consciously acquire the advanced knowledge about how to improve their livestock and fatten their cattle and sheep. Furthermore, they are actively participating in government-organized training programs such as "Introducing Science and Technology to Pastoral Areas" and "Livestock Improvement". These programs allow the herders to strive for better policy support and continuously improve their craft, as well as their ability to use the technology. Therefore, many typical families who were relatively successful in the management of their household production appeared in the East Ujimqin Banner region, including those who specialized in areas such as structural adjustment of herds, ram breeding, delivering lambs in early spring, lamb fattening, Simmental cattle breeding, yellow cattle improvement, and Mongolian horse breed conservation. These families were issued certificates as rewards by the Bureau of Agriculture and Animal Husbandry. During the study, I found that medals became a special part of the landscape in homes of many herders, with titles such as "Standardized Herd of Ujimqin Sheep", "Model Household for the Promotion of Agricultural Machinery" and "Ujimqin's Best Ram Rearing". Below is an example of a typical family specializing in Simmental cattle breeding. 


\section{Case 5}

Wuliji, a 46-year-old ethnic Mongolian herder from Jirigalang Gacha, Enhe, Wuliyasitai town. His family of five was allocated 11,040 mu of grassland, where they raise 610 sheep. Since 2005, Wuliji has invested 30,000 yuan in building 4 warm cattle sheds made of brick and tile covering $200 \mathrm{~m}^{2}$, installing a motorpumped well and renovating the necessary winter infrastructures, including livestock sheds and water wells. At the same time, he has adjusted his herd's compositional structure and improved the breeds of his livestock, making Ujimqin sheep the priority. In 2007, he then removed 200 goats and 20 cows to adjust the structure to accommodate more sheep. From the original total of 610 sheep, the 230 that were in poor condition, had low meat yields, or small tails were all slaughtered. The remaining 380 sheep were raised as breeding ewes. On this basis, he also changed his former practice of allowing the sheep to inbreed, by mating within their immediate blood relations. Instead, he implemented the "cross breeding" method to avoid the degeneration of sheep breeds due to inbreeding. Every 3 years, he selects a number of breeding rams with a good bodily condition, high meat yield, high production rates and large tails from another herd of non-blood related sheep to mate naturally with his own ewes. By doing so, he can gradually improve the level of purebred Ujimqin sheep in his flock. After several years of hard work, each sheep can yield 15-20 jin more, achieving prices 45-60 yuan higher than before. At present, from the 240-260 lambs delivered each year, he selects 50-60 ewe lambs of good bodily condition and with large tails to replenish his stock of breeding ewes. The rest of the lambs are all slaughtered or sold in the same year. The family annual net income from sheep sales can be as high as 50,000 yuan.

This case suggests that in order to modernize animal husbandry, local herders are making every effort to learn the latest farming technology and expertise, transforming the traditional way of viewing and managing their businesses. After examining their past experience of breeding, herders took a number of measures: infrastructures were enhanced; the percentages of breeding ewes and rams in the herd were adjusted; and cross breeding was introduced to improve the livestock's genetic purity. As a result, there is a higher proportion of good quality livestock in the farms, and the wellknown Ujimqin Sheep are even purer than before. These phenomena are demonstrative of a positive reform in how the herders think and operate when managing their fields. By utilizing more natural, economic and social capital, they are trying to adapt to the trend of modernization in this industry and pursuing sustainable methods of development through which to live in harmony with nature. Obviously, what we have seen so far are all examples of endogenous development, for the economic strategies are made by individuals or families themselves. This active model shows a marked difference from the passive development that is driven by external policies.

Leaving the land, but not the countryside: diversified operations and independent development beyond the grassland

The phrase "Leaving the land without leaving the countryside" refers to the demographic transition that is taking place among the agricultural population; the 
processes of urbanization and modernization are taking this from an agricultural population to a non-agricultural one, without removing them from their agricultural land. This is achieved mainly through developing non-agricultural land management in rural areas, and through small towns absorbing the rural population who leave their farmlands. In effect, this increases the number of people who live in the countryside, but do not work in agricultural production (Zhao Xishun 1984: 11). Many scholars have viewed this as a route to urbanization that would be suited to China's national conditions. They argued that, with a monumental population and thus a deficiency in per capita area of arable land, we would inevitably see employment problems as the population transitions from a large amount of rural surplus labor to a non-agricultural population. Furthermore, in reality it is impossible for the Chinese government to invest more into setting up new factories to absorb the newly-created non-agricultural population. Therefore, the localized demographic transition taking place within the agricultural population is a vital solution for China to achieve urbanization.

By the end of 2019, China had an urban population of 848.43 million, and a rural population of 551.62 million, which accounts for 60.6 and $39.4 \%$ of the country's total population respectively. ${ }^{7}$ As the country undergoes urbanization, it would be impossible for the limited number of large and medium sized cities to absorb this entire rural population of over 500 million people. Chinese government has put forward a series of policies highlighting the need to transfer the large amount of rural surplus labor to cities and towns. This is necessary in order to revitalize rural development and achieve urbanization. However, what awaits the rural area if all its residents are gone? To this end, we must carefully examine the ways to guide and coordinate positive interaction and balanced development between the urban and rural areas. Meanwhile, the resources of urban areas should be made available to rural areas when appropriate, thus enhancing the integrated development between the two.

With the regard to the development of the pastoral areas in the East Ujimqin Banner, as the traditional forms of livestock farming gear themselves towards modernization, there will be a decrease in the amount of labor needed to produce the same amount of livestock products as before, due to the increase in productivity. At the same time, the emergence of a large number of specialized livestock farming cooperatives will inevitably lead to an intensification and up-scaling in livestock production. The integration of resources will also cause a gradual swell in the surplus labor force. The utilization of this surplus labor will become a problem. If these newly unemployed individuals moved into town, they would encounter difficulties in their family lives, as they have long been accustomed to the nomadic way of life and cannot easily blend in with the new way of life in urban areas. Therefore, the abovementioned localized demographic transition is currently a relatively plausible model for completing the transformation of the nomadic population into an urban population. Without the surplus labor needing to leave their grassland, they can be combined with other production conditions beyond the grassland to stimulate the initiative of producers and promote self-sufficiency,

\footnotetext{
${ }^{7}$ National Bureau of Statistics of China: http://www.stats.gov.cn/tjgz/tjdt/, 2020-03-27
} 
causing the production methods of pastoral areas to turn towards diversification and endogenous development. All this can be done without the surplus labor needing to leave their grassland. This will require the local government to utilize this surplus labor force to boost development in other industries in the pastoral areas, while encouraging herders to step up livestock production, thus establishing a multi-sectoral economic structureis suitable for pastoral development. As part of this, the government can encourage herders to develop the local cultural industries, building a culturally rich pasture based on the region's own traditional systems of knowledge. The subject of Case 6, Siqintuya is a perfect example of the East Ujimqin Banner's many impressive entrepreneurs working in the ethnic cultural sector. Led by Siqintuya, several lovers of sewing established the "Shuangyi" Ethnic Clothing Sewing Center, now famous in the East Ujimqin Banner.

\section{Case 6}

Siqintuya is a 45-year-old ethnic Mongolian herder from the Taosen Baola Gegacha, the Samai Sumu. She has a dexterous hand and is a naturally talented person. With the teaching of elders and her own hard work, she became skilled in the production of ethnic clothing. Initially, she became the preferred tailor for herders in the Gacha village because of her fine workmanship, and her skill of infusing fashion into the making of traditional clothes. Later, as more and more people were asking her to make Mongolian robes for them, the business grew bigger and bigger and it became difficult for her to manage it all by herself. Therefore, to expand the business, she decided to bring her household production of ethnic clothing into the market and undergo expansion. In June 1997, she led the other female herders from Gacha village in founding the "Shuangyi" Ethnic Clothing Sewing Center, located in the East Ujimqin Banner. The Center also took 14 hobbyists into its ranks. To facilitate the development of the Center, she consulted experts in Hohhot and even as far as Beijing and Shanghai. She surveyed the market, and sought the support of preferential government policies on the transfer and employment of herders as workers. In terms of the Center's production, garment processing falls into two parts based on the technical characteristics of the processors, i.e., garment construction and embroidery. Siqintuya herself is in charge of ordering and quality assurance. With the efforts of Siqintuya and the hobbyists, "Shuangyi" has grown into a large garment processing plant. Each year, they sew more than 300 pieces of ethnic clothing and attend many ethnic clothing exhibitions and performances, both in and outside of the Banner.

Siqintuya's ethnic garments produced at the "Shuangyi" Ethnic Clothing Sewing Center have gained serious recognition. For example, in July 2002, the Center won an Excellency Award at the first East Ujimqin Banner "Bai Ce Shu" Nadam Fair for Ethnic Arts and Culture; in January 2005, her ethnic clothing won third prize for Mongolian ethnic clothing at the East Ujimqin Banner "Winter Nadam Fair" Art Exhibition; and in November 2005, she attended the exhibition on the 9th Women's Representatives' Conference of the Inner Mongolia Autonomous Region on behalf of the East Ujimqin Banner Women's Federation. Furthermore, in January 2006, her design works were highly popular at the Region's first Arhada 
Cup Ujimqin Clothing Design and Performance Contest, winning second prize in design and a prize for being one of the "Top Ten Design Works".

Now, two new training centers have been established in her garment factory: the East Ujimqin Banner Reemployment Training Center for Women and the Ethnic Clothing Craftsmanship Training Center. In the past 2 years, more than 80 women completed training in these training centers, and while a number of trainees have stayed on to work at the center, most trainees have started up their own traditional ethnic clothing shops after completing their training. This approach is an effective response to the pressure on local herders to set up businesses in their native regions. So far, more than 20 trainees have set up their own business on making ethnic clothing. The income of Siqintuya's clothing center is increasing year by year. In 2012 alone, the factory's revenue reached RMB 220,000. RMB 120,000 was paid to employees in salaries, leaving a net income of RMB 100,000.

Without leaving the grassland where she was born, the subject of this case study, Siqintuya successfully established a sewing center for ethnic clothing, featuring traditional craftsmanship and attracting many like-minded hobbyists in the process. Her story sets a perfect example for the localized demographic transition behind the idea of "leaving the land without leaving the countryside". She managed to innovate traditional economic practices, using methods that were specifically suited to the local conditions. Consequently, projects like this help to advance the positive reorganization of both the economic and demographic structure of the pastures, meanwhile preserving traditional ethnic culture. Furthermore, the surplus labor from the livestock production industry, which are, in this case, herders leaving the grassland, have better options available to them. As described by Siqintuya, the ethnic clothing they make is mainly all for sales purposes, but the designing and studying that they do every day is extremely beneficial towards preserving the near-extinct traditional craftsmanship used in the making of Ujimqin clothing.

\section{Case 7}

Sarina, a 39-year-old ethnic Mongolian herder from Dabuxilatu Gacha, Wuliyasitai Town. In 2002, Sarina decided to reorientate production, in order to alleviate the problems brought about by the grassland degradation, such as a lower family income and the increasing difficulty of making a living. She sold all of her livestock and enclosed her $3000 \mathrm{mu}\left(2000 \mathrm{~km}^{2}\right)$ of allocated grassland to set up the "Ujimqin Dairy Franchise Station". In 2005, aiming to expand the scale of production, Sarina purchased a series of processing equipment used for fermentation, milk refining, molding, and air drying. As for the sources of her milk, in addition to her own dairy cattle, she also purchased about 1000 jin of fresh milk per day for 1.00 yuan per jin from the dairy farmers in the Suen Baolige community. Due to the large amount of processing and production needed, and the lack of a sufficient workforce, she hired three herders from Gacha with a monthly salary of 400-600 yuan. The Station currently produces over 300 jin of dairy food products every day, with a gross income of around 1000 yuan. In June 2006, Sarina registered the trademark of "Zhusaleng". Then, by continuously improving product packaging and integrating the products into grassland tourism, Sarina was able to gradually 
build up the East Ujimqin Banner's dairy farming cultural industry by integrating production and marketing within one operation. In recent years, over 10 herders from Gacha have found employment at the station as the industry develops and expands.

By selling her milk products on the market, Sarina has set the standard for the other young herder entrepreneurs of Dabuxilatu Gacha. Under her influence, more and more young herders have begun to experiment with diversified business management and independent development beyond animal husbandry. To a certain extent, these efforts have promoted the transformation of Gacha herders' methods of production and management, stimulating pastoral economic development in the East Ujimqin Banner. In recent years, under the guidance and encouragement of the local government, Mongolian clothing, leather boots, bone carvings, saddles and other manufacturing workshops have sprung up all over the streets of East Ujimqin Banner. Herders strive to maintain nomadic lifestyles while consciously inheriting their national culture. Their domestic space is also expanding with economic activities, bringing advanced resources and technologies back to the grassland after "leaving home" in the short-term, so as to better engage in the animal husbandry economy "without leaving the land". Herders constantly and flexibly adjust their family strategies, but always adhere to the tradition of "making a living" directly from the grassland (Fei Xiaotong 1998).

The localized transition mainly relies on the local people themselves. Combining the natural and cultural characteristics of the pastoral area, vigorous work is underway to develop the productivity of animal husbandry and to improve the herders' independent management methods and development capabilities. People are now trying to break away from the single economic structure of the pastoral area, so as to combine animal husbandry with other professions to promote coordinated development between each sector. In this way, it could be possible to avoid the outflow of labor force, capital, raw materials and traditional culture, which is usually caused by the regional economic development rigidly driven by the growth of large and medium-sized cities and towns. Meanwhile, the gap between herders and urban residents could also be narrowed, both in terms of productivity and ideology. Therefore, we can conclude that the multi-occupational structure, constructed deliberately by local herders and adapted to grassland ecology, further demonstrates the various possibilities of social development in pastoral areas. They are striving to make their own voices heard in the national discourse on development, taking advantage of their existing natural and social capital to actively improve their ability to develop economically, and constructing a set of behavioral strategies that are suitable for the modern market economy.

\section{Conclusions: another perspective on endogenous development}

The above ethnographic cases reveal how the once isolated pastoral society at China's northern frontier is able to respond to the government's standpoint on modernization and effectively put this standpoint into practice. Local society 
refused to passively develop, striving instead to actively adapt itself to new conditions. Working with the family as the central unit, local people were able to constantly change and adapt their ways of life. They actively transformed their concepts of development, adjusted herd structures, promoted livestock improvement, and carried out lamb fattening. Pastoral society has been striving to learn new skills, incorporate technology into traditional livestock production, and even extend their business beyond the nomadic economy. Based on local traditional knowledge, they have independently developed their minority ethnic cultural industries and created a broader range of survival strategies that combine the traditional with the modern. The concept of active development can be seen clearly in the process of modernization undergone in the pastoral areas of the East Ujimqin Banner. Their practices beg further reflection on the previous concept of stimulating development from outside a community.

The autonomous development that is suitable for this ethnic group's personal and cultural characteristics may be an appropriate basis for the development of wider pastoral society. The concept of "endogenous development", put forward by Professor Tsurumi from Japan's Sophia University in the 1980s, provides inspiration for how today's pastoral societies will develop in the future. It is a theory that emphasizes taking full advantage of the natural and social resources from within a region in order to give full play to the consciousness and subjectivity of the local people. In short, this is an approach that attaches importance to development that is triggered from within a community. At present, a number of questions arise given the context of the implementation and promotion of the Rural Revitalization Strategy. How best to transform such vast pastoral areas? How can we strike a balance between modernity and local issues in the discourse of development, so as to better integrate the development of the first, second, and third sectors together as one? In formulating policies aimed towards the economic development of ethnic areas, close attention must be paid to the development demands and spiritual worlds of local societies. We must seek to deeply understand each local society, both in its particular details and its overall nature. Policies should give full play to the traditional mechanisms of the local culture, giving substantial consideration to the histories, cultures, and realities that circulate there. We must not act blindly as we implement the abolishment of the dual urban-rural structure. If we eliminate small farm and small pastoral economy to radically speed up China's urbanization, we run the risk of casting farmers and herders into urban slums and robbing them of their sustainable traditional livelihoods.

The study shows that cultivating the ethnic minorities' own development mechanisms and fostering their initiative to take part in development is an effective and beneficial measure. Otherwise, economic growth and development can only be a short-term expansion in scale, unable to sustain itself sufficiently to support the ethnic minorities' long-term development. There is evidence to prove that local society tends to understand development and can practice transformation through their own original social and cultural systems. Under the new circumstances, the endogenous development among the pastoral herders of the East Ujimqin Banner is now a survival practice that is based on 
traditional nomadic life and the reconstruction of local knowledge. This set of practical strategies combining traditional and modern development not only connects pastoralists with the external market and the nation as modes of production, but also enables the livelihoods of local societies to be maintained and traditional social culture to continue despite the ever-changing impacts of modernization.

Acknowledgements Not applicable.

\section{Authors' contributions}

$\mathrm{KZ}$ is responsible for paper writing, idea design, field research, etc., while HS participate in field research, data collection, etc. The author(s) read and approved the final manuscript.

\section{Funding}

Inner Mongolia philosophy and social science planning project: "Research on the family livelihood and diversified cooperation of East Ujimqin Banner" (Item Number: 2015C123).

\section{Availability of data and materials}

Available from the author upon request.

\section{Ethics approval and consent to participate}

Not applicable.

\section{Consent for publication}

Not applicable.

\section{Competing interests}

We have no any competing interests.

\section{References}

Chongqing, Wu (吴重庆). 2016. Endogenous development and poverty alleviation《内发型发展与开发扶贫 问题》. New Horizons from Tianfu《天府新论》(6).

Declaration of Madrid. 2006. International conference on a culture of peace, 2000 [EB/OL]. http://www.un. org/documents/ga/docs/56/a5656.pdf. 
Jiange, Wang (王建革). 2001. Herd structure and pastoral economy of the Mongolian Ethnic Group in Modern Times《畜群结构与近代蒙古族游牧经济》. Agricultural History of China《中国农史》(2).

Kazuko, Tsurumi, and Kawata Tadash. 1989. The theory of endogenous development. Tokyo: University of Tokyo Press.

Lattimore. 2005. Inner Asian frontiers of China [M]. Translated by Tang Xiaofeng (唐晓峰), Nanjing: Jiangsu People's Publishing House江苏人民出版社.

Linstone H. A. 1979. Another development: approaches and strategies. Nerfin M. ed. Dag Hammarskjöld Foundation, Technological Forecasting \& Social Change 13(1).

Loye. 2004. The evolutionary outrider. Translated by Hu Enhua (胡恩华) et al. Social Sciences Academic Press 社会科学文献出版社.

Renmeng, Tu (涂人猛). 1993. The origin and development of endogenous rural development theory 《内源式 乡村发展理论的渊源及发展》. Economic Review《经济评论》(4).

Shupin, Huang (黄淑娉), Peihua, Gong (龚佩华). 1998. Theoretical research on cultural anthropology《文化 人类学理论方法研究》. Guangzhou: Guangzhou Higher Education Press广州:广东高等教育出版社.

Xiaotong, Fei (费孝通). 1993. Reflections on the social and economic development of ethnic minorities in the border regions《边区民族社会经济发展思考》. Institute of Sociology and Anthropology in Peking University北京大学社会学人类学研究所. East Asian Social Study《东亚社会研究》.Beijing: Peking University 北京:北京大学出版社.

Xiaotong, Fei (费孝通). 1998. From the soil, childbirth system《乡土中国生育制度》.Beijing: Peking University Press 北京:北京大学出版社.

Xiaotong, Fei (费孝通). 2000. The changes in Chinese society over the century and the cultural consciousness in the process of globalization - speech on international anthropology academic seminar on human existence and development in the $21^{\text {st }}$ century 《百年中国社会变迁与全球化过程中的“文化自觉” 一在“21世纪人类生存与发展国际人类学学术研讨会”上的讲话》. Journal of Xiamen University (Arts \& Social Sciences Edition)《厦门大学学报》(哲学社会科学版) (4).

Xishun, Zhao (赵喜顺). 1984. On “Leave the land but not the home”《论“离土不离乡”》. Social Science Re$\operatorname{search}$ 《社会科学研究》(4).

Xueyi, Lu (陆学艺). 2001. Endogenous village《内发的村庄》.Beijing: Social Science Press 北京:社会科学 出版社.

\section{Publisher's Note}

Springer Nature remains neutral with regard to jurisdictional claims in published maps and institutional affiliations. 